\title{
Ultrasound-targeted nanoparticle delivery across the blood-brain barrier
}

Richard Price

From Current and Future Applications of Focused Ultrasound 2014. 4th International Symposium Washington, D.C, USA. 12-16 October 2014

\section{Background/introduction}

The delivery of systemically administered drugs and genes to the CNS is hindered by both the blood-brain barrier (BBB), which limits transport from the bloodstream to the brain to only a few privileged molecules, and the nanoporous electrostatically charged tissue space, denoted here as the "brain tissue barrier" (BTB). Our group engineers targeted drug and gene delivery approaches, capable of overcoming both of these physical barriers, for the treatment of brain tumors and neurodegenerative diseases. We focus on nanoparticle (NP) delivery systems, as they offer the potential for enhanced transfection efficiencies and controlled-drug release.

\section{Methods}

To deliver drug- and gene-bearing NPs across the BBB, we use focused ultrasound (FUS) and contrast agent microbubbles (MBs). FUS may be applied using either MR-guidance or with a simple table-top system. We and others have shown that activating MBs with FUS yields safe and transient BBB opening in the FUS focal zone. Technologies for overcoming the BTB center on coating

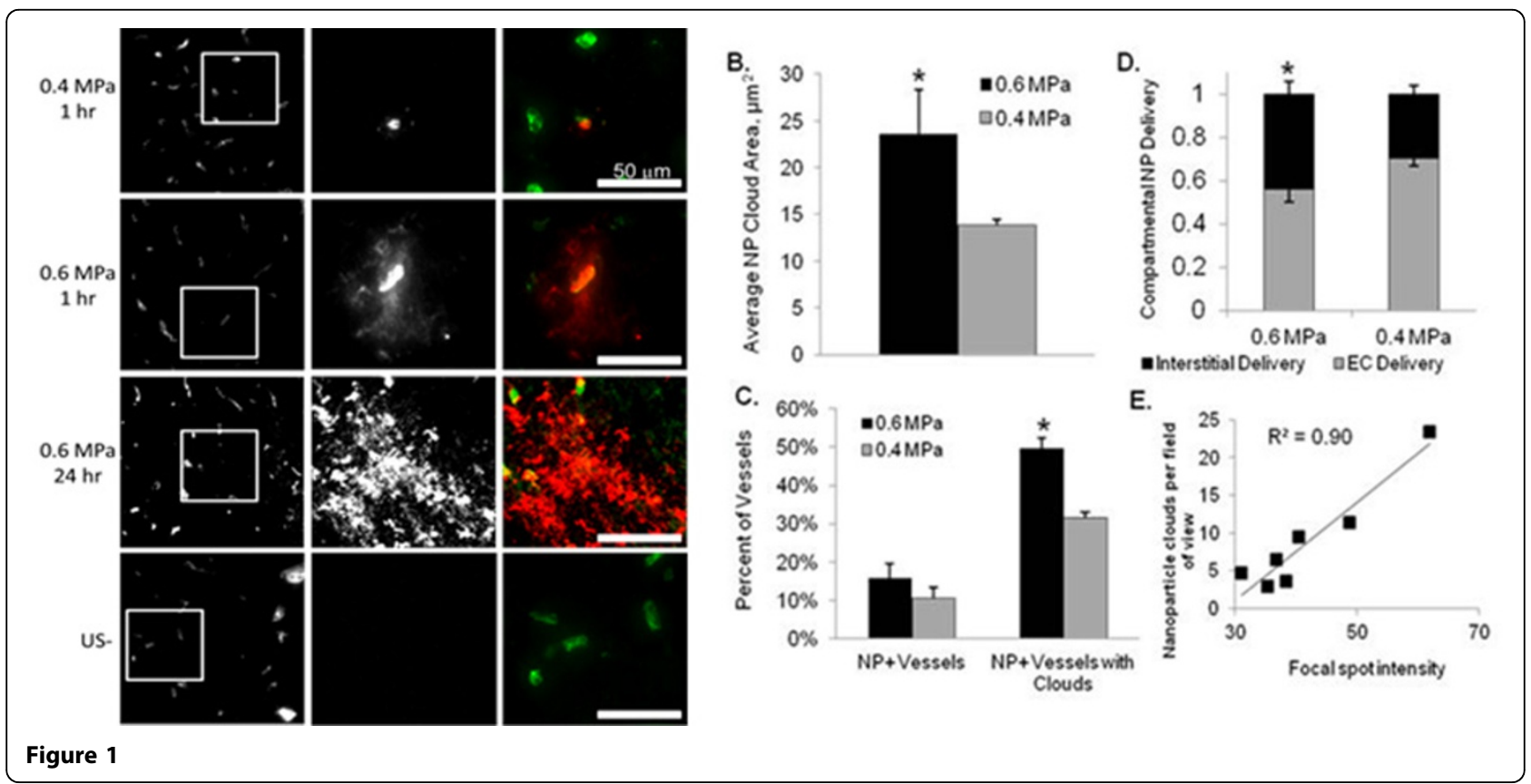

University of Virginia, Charlottesville, Virginia, United States 


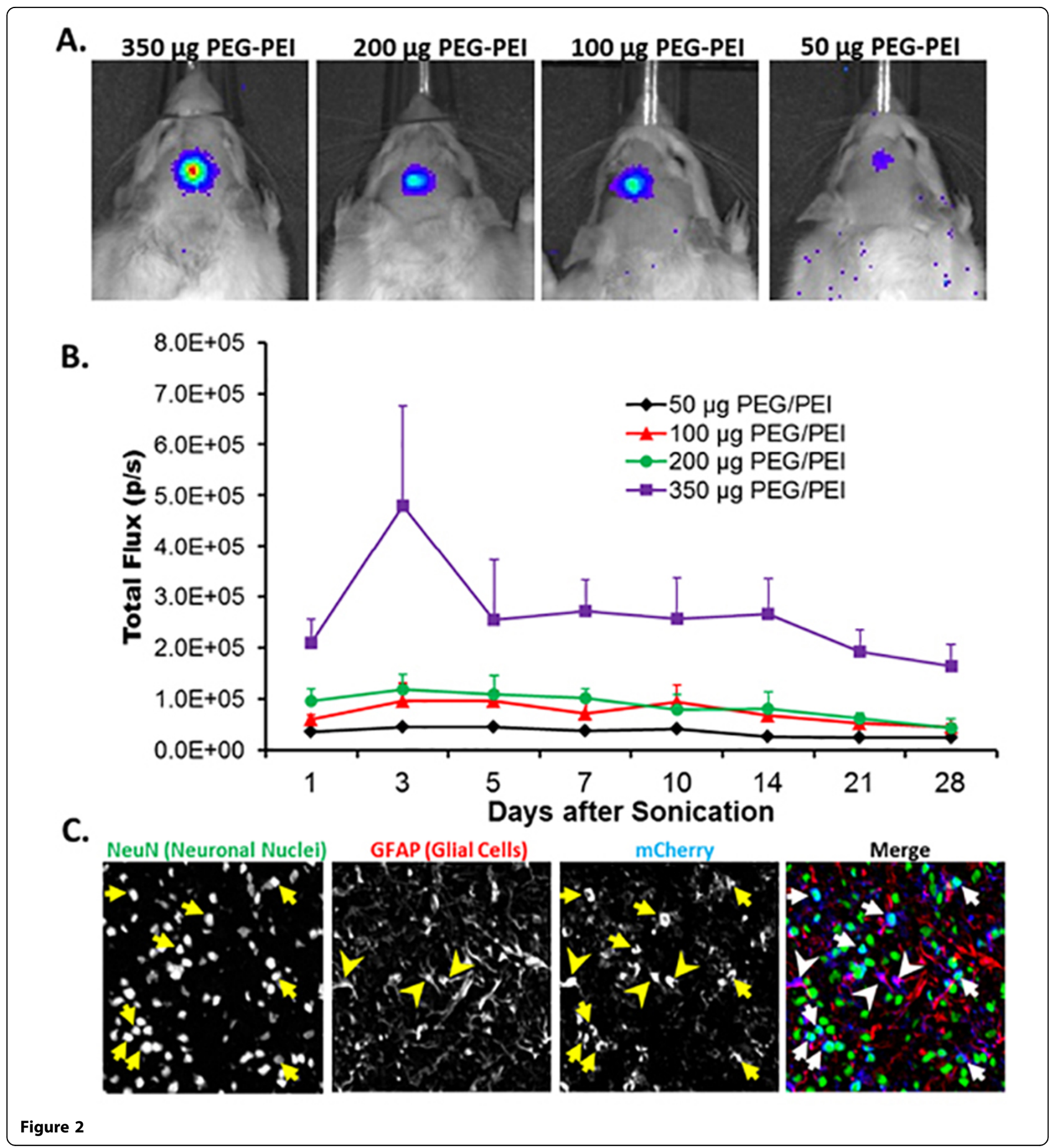

the drug and gene bearing NPs with an extremely dense brush layer of polyethylene glycol (PEG). NPs are injected at the time of $\mathrm{BBB}$ opening to permit their delivery to the CNS.

\section{Results and conclusions}

Drug Bearing NP Delivery - PEG-coated polystyrene (PS) tracer NPs (60 $\mathrm{nm}$ diameter) and biodegradable polylactide-co-glycolide (PLGA) NPs $(75 \mathrm{~nm})$ were engineered to penetrate brain tissue and then delivered across the BBB in rats using $1 \mathrm{MHz}$ FUS. NPs were delivered to endothelium and as "clouds" to brain tissue. PS-NP delivery through the brain continued over 24 hours, yielding enhancements of cloud size and intensity (Figure 1A). FUS at 0.6 MPa delivered a larger fraction of PS-NP to the interstitial space (Figure 1D) and 
increased PS-NP coverage area (Figure 1B). The percentage of PS-NP+ vessels producing clouds was increased $(\mathrm{P}<0.05)$ to $50 \%$ at $0.6 \mathrm{MPa}$ (Figure $1 \mathrm{C})$. The higher US pressure produced a significant 4.6 -fold increase in large (i.e. $>200 \mu \mathrm{m} 2$ ) PS-NP clouds. Focal spot intensity on MRI predicted the number of PS-NP clouds (Figure 1E). We also verified that BBB opening with MBs and FUS at $0.6 \mathrm{MPa}$ can be used to substantially increase $60 \mathrm{~nm}$ PS-NP delivery to intracranial 9L rat tumors.

Gene Bearing NP Delivery - We used a blend of nonPEGylated and highly PEGylated polymers at an optimized ratio to engineer brain-penetrating DNA NPs with a polyethylenemine (PEI) core polymer. We delivered PEI-NPs $(\sim 50 \mathrm{~nm}$ in diameter) carrying either luciferase or mCherry plasmid DNA (driven by the unmethylated CpG-free $\beta$-actin promoter) across the BBB in rats using MR-guided FUS and MBs. Robust luciferase transgene expression, corresponding to a single focal site of FUS exposure, was visible (Figure 2A), and the intensity of gene expression was correlated with PEI-NP concentration (Figure 2B). After delivering mCherry PEI-NPs across the BBB with FUS and MBs, we immunochemically detected mCherry in both glial cells (GFAP, red) and neuronal cell nuclei (NeuN, green) (Figure 2C). mCherry expression was homogeneously distributed throughout the sonicated area (Figure $2 \mathrm{C}$ ), demonstrating the benefit of combining FUS-mediated delivery across the BBB with brain-penetrating NPs. We believe these studies represent the first evidence for brain transfection via the delivery of a nonviral gene NP across the BBB with FUS. Going forward, this approach may be used to deliver genes for neurotrophic factors for the treatment of neurodegenerative diseases.

\section{Acknowledgements (Funding)}

Supported by NIH CA164789, NIH EB016784, and the Focused Ultrasound

Foundation.

Published: 30 June 2015

doi:10.1186/2050-5736-3-S1-020

Cite this article as: Price: Ultrasound-targeted nanoparticle delivery across the blood-brain barrier. Journal of Therapeutic Ultrasound 20153 (Suppl 1):O20.

\section{Submit your next manuscript to BioMed Central} and take full advantage of:

- Convenient online submission

- Thorough peer review

- No space constraints or color figure charges

- Immediate publication on acceptance

- Inclusion in PubMed, CAS, Scopus and Google Scholar

- Research which is freely available for redistribution

Submit your manuscript at www.biomedcentral.com/submit 